Paper 1

\title{
Presenting the Case for the Application of Multi-Criteria Analysis to Mega Transport Infrastructure Appraisal
}

\section{Harry T. Dimitriou*, E. John Ward and Marco Dean}

OMEGA Centre, Bartlett School of Planning, University College London,

14 Upper Woburn Place, London, WC1H 0NN, United Kingdom.

E-mail addresses: h.dimitrou @ucl.ac.uk (H.T. Dimitriou), eric.ward@ucl.ac.uk (E.J. Ward), marco.dean.11@ucl.ac.uk (M. Dean).

* Corresponding author

\begin{abstract}
The paper commences with an overview of mega transport infrastructure decision-making as it relates to the megaproject development cycle and challenges of sustainable development which are increasingly redefining the criterion for the evaluation of project success. The body of the paper presents a brief critique of various appraisal applications to mega transport infrastructure projects, including: Social Cost Benefit Analysis; Cost Effectiveness Analysis; Goal Achievement Matrix Methods and the Planning Balance Sheet, highlighting the merits and demerits of the outlined approaches. Here particular reference is made to the power of context on decision-making and other lessons from OMEGA Centre research. These include, most importantly, the treatment of risk, uncertainty and complexity of developments outside of the project and the challenges of meeting multiple stakeholder aspirations/needs thereby building up the case for the introduction and use of multi-criteria analysis and policy-led multi-criteria analysis to the appraisal of MTPs.
\end{abstract}

Keywords: project appraisal, challenges of sustainable development, social cost benefit analysis, multiple criteria analysis

JEL: R4 D61 D63

\subsection{Introduction}

Special 2016 Edition of The Journal of Research in Transportation Economics

'The Application of Policy-led Multi-Criteria Analysis to Megaproject Transport Infrastructure Appraisal' 
Project appraisal (often referred to as ex-ante project evaluation) may be seen as a process of exploration, review and evaluation of a proposed course of action(s) carried out by a party (or several parties) to determine whether a given proposal is viable. It is typically undertaken on behalf of a decision-maker in pursuit of the interests of project investors in line with a given set of objectives (Rogers and Duffy, 2012). This paper examines this process in some depth as applied generically and, more specifically, to mega infrastructure projects and mega transport projects (MTPs) in particular. This is done with a view to drawing out lessons for MTP decision-making as a basis for presenting the case for the application of Policy-Led Multi-Criteria Analysis (PLMCA) ${ }^{1}$ to the appraisal of such projects.

It has been argued that during the last century project appraisal relying on rigorous quantitative and economic methodologies, especially for infrastructure, has become increasingly embedded in notions of the project lifecycle, replacing earlier more classic methods based on 'survey-analysisplan' (see later discussion and Olivera and Pinho, 2010). The need for more informed advice and guidance on decision-making for major infrastructure investments (especially MTPs) (see Munda et al., 1994; Alexander, 2006a and 2006b; OMEGA Centre, 2010) has grown hand in hand with increases in their size and complexity, and their rising importance to global and local economies. The case for more rational informed choices has also been advocated on grounds of decreasing investment resources, high opportunity costs and a growing demand to better understand the impacts of such projects (both negative and positive) to the economies, communities and territories they serve and traverse (Priemus, 2008; OMEGA Centre, 2012).

Numerous project appraisal methods have been proposed and developed for infrastructure developments since the early decades of the twentieth century; many conceived as responses to perceived shortcomings of earlier methodologies (see later discussion and McAllister, 1982; Sager, 2003). Several authors have attempted to group these methods into a variety of different systems of classification (see Guba and Lincoln, 1989; Söderbaum, 1998). One of the simplest classifications distinguishes such methodologies in two general groups (see Rogers and Duffy, 2012). The first includes methods which primarily attempt a monetary appraisal of all criteria relevant to the decision. Examples here are Cost-Benefit Analysis (CBA) and its common variants, including financial, economic and social cost benefit analysis (SCBA) (see Section 1.3 below). The second category comprises appraisal methods seeking to take into account multiple dimensions of a decision problem explicitly considering both monetary and non-monetary costs and benefits, expressed in quantitative and qualitative terms. Methodologies pertaining to the second type

\footnotetext{
${ }^{1}$ PLMCA is here defined as an eclectic framework and attendant set of processes for undertaking multiple project stakeholder analysis and trade-offs in decision-making (led by policy guidelines) that facilitate key decision-takers arrive at more integrated and sustainable investments that are more strategic, comprehensive, robust and transparent in character than those primarily reliant on traditional project appraisal methods (Dimitriou, 2013).
}

Special 2016 Edition of The Journal of Research in Transportation Economics

'The Application of Policy-led Multi-Criteria Analysis to Megaproject Transport Infrastructure Appraisal' 
Paper 1: Presenting the Case for the Application of Multi-Criteria Analysis to Megaproject Infrastructure Appraisal Harry T. Dimitriou, E.John Ward and Marco Dean

include: Cost-Effectiveness Analysis (CEA), the Planning Balance Sheet (PBS) and the Goal Achievement Matrix (GAM) (see Section 1.4 below). It could be argued that the latter two may be seen to be variants of CBA methods of appraisal or at least can be positioned on the border between the two general classes of methodologies alluded to above. In these terms, these methodologies can be considered as the earliest attempts to reform/ inform CBA, even though they all maintain some elements of CBA in their frameworks (Rogers and Duffy, 2012). The main difference between CBA and MCA, including more traditional applications of MCA and PLMCA, is that the former are essentially guided by economic efficiency criteria relying upon the pricing of attributes by the market (albeit with adjustments) while the latter is ultimately led by objectives or policies, the outcomes or impacts of which do not necessarily lend themselves to market pricing and/or monetisation.

The origins of the development and application of MCA lie in the fact that whilst CBA and other traditional monetary-based appraisal techniques have had a long history of application to infrastructure projects, especially transport projects, they have in many cases (some argue too many) proven to be less than satisfactory (see Hook, 2011; Litman 2008 and 2013). Their failure to properly take account the distributional consequences of projects is one of the most serious deficiencies of conventional CBA (OECD, 2006). This has especially been the case for large-scale infrastructure projects which typically entail complex decision-making and encounter numerous problems associated with the need to address multiple (sometimes conflicting) objectives of numerous project stakeholders (van Wee and Tavasszy, 2008). Here the work of Stirling (2008a) concerning stakeholder participation in the social appraisal of technology projects offers some interesting insights and parallels for the infrastructure field into how participatory project decisionmaking could be introduced.

On account of recent experiences associated with the global credit crises and the growing acknowledgement of broader sustainable development challenges, major infrastructure projects have gained additional attention in relation to their ecological, spatial, social (including austerity) impacts, as compared to more conventional economic concerns. This has led to a reconsideration of the validity of the premise that all significant costs and benefits of project outcomes should be (and can be) monetised and/or quantified, especially in the context of MTPs. It has also highlighted yet again equity concerns regarding the 'winners' and 'losers' of such projects, and whether project gains and losses can be adequately appraised by the use of monetised values. This déjà vu perspective has us returning to many arguments first raised in the 1960s, if not earlier, associated with notions of the limits to growth and questions of the legitimacy of pursuing economic growth at any cost (see Meadows et al, 1972; Mishan, 1967, respectively). These developments also revisit earlier appraisal concerns regarding the distribution of benefits, notions of welfare economics and the role of the market (see Little, 1950; Peters, 1968; Dobb, 1970), more recently elaborated on by Adams (1995), Pierce (2002) and Kay (2003) among others (see later discussion in Section 1.3.1).

Special 2016 Edition of The Journal of Research in Transportation Economics

'The Application of Policy-led Multi-Criteria Analysis to Megaproject Transport Infrastructure Appraisal' 
In seeking to ultimately explain why MCA (especially PLMCA) approaches to infrastructure project appraisal and MTPs in particular have been developed, what their merits are, and what are the relationships they retain with $\mathrm{CBA}$ plus other techniques that have emerged to broaden project appraisal beyond CBA's economic focus, the discussion which follows commences with an explanation of the role of appraisal in the project cycle. It then alludes to a number of challenges encountered in appraisal exercises for mega infrastructure projects. It subsequently provides a brief account of the rationale of CBA and its procedures, culminating in offering an overview of its main assets and limitations as a basis for the search and development for broader project appraisal methods that may be applied to MTPs especially. The strengths and weaknesses of each type of appraisal methodology are briefly presented with a view to presenting the case for the application of MCA, more particularly PLMCA, as a more suitable approach for the 21st Century practice of megaproject infrastructure appraisal both generically, but more especially for the transport sector.

\subsection{The project cycle and the role of appraisal}

\subsubsection{The appraisal and evaluation cycle}

The project cycle (sometimes referred to as the 'project lifecycle') irrespective of its size, cost and sector, consists of sequences of phases through which a project evolves from an initial idea to a completely structured and implemented scheme (Patel and Morris, 1999). Both the number and the labelling of these stages vary depending upon which particular discipline/field is being considered (Wideman, 2004). It is however possible, more generally, to assimilate eight phases (see Figure 1) to a project cycle consisting of: project conception, project planning, project ex-ante evaluation (otherwise referred to as appraisal), project implementation, project operation, project ex-post evaluation, project monitoring and project closure (Chapman and Ward, 2011). Within each of these, elements of decision-making take place in the form of appraisal and evaluation ${ }^{2}$, often in an iterative way, depending upon the maturity of the project. It is possible to map the steps of such an iterative appraisal and evaluation cycle alongside those of the project cycle, but it is first necessary to define a typical appraisal process (the focus of this paper's discussion). The UK government's Green Book (HM Treasury, 2003), for instance, considers six different phases in the project life cycle formalized in the acronym ROAMEF (standing for Rationale, Objectives, Appraisal, Monitoring, Evaluation and Feedback) as compared to the eight shown in Figure 1.

\footnotetext{
${ }^{2}$ Where appraisal represents project ex-ant evaluation and evaluation represents project ex-post evaluation.

Special 2016 Edition of The Journal of Research in Transportation Economics

'The Application of Policy-led Multi-Criteria Analysis to Megaproject Transport Infrastructure Appraisal' 


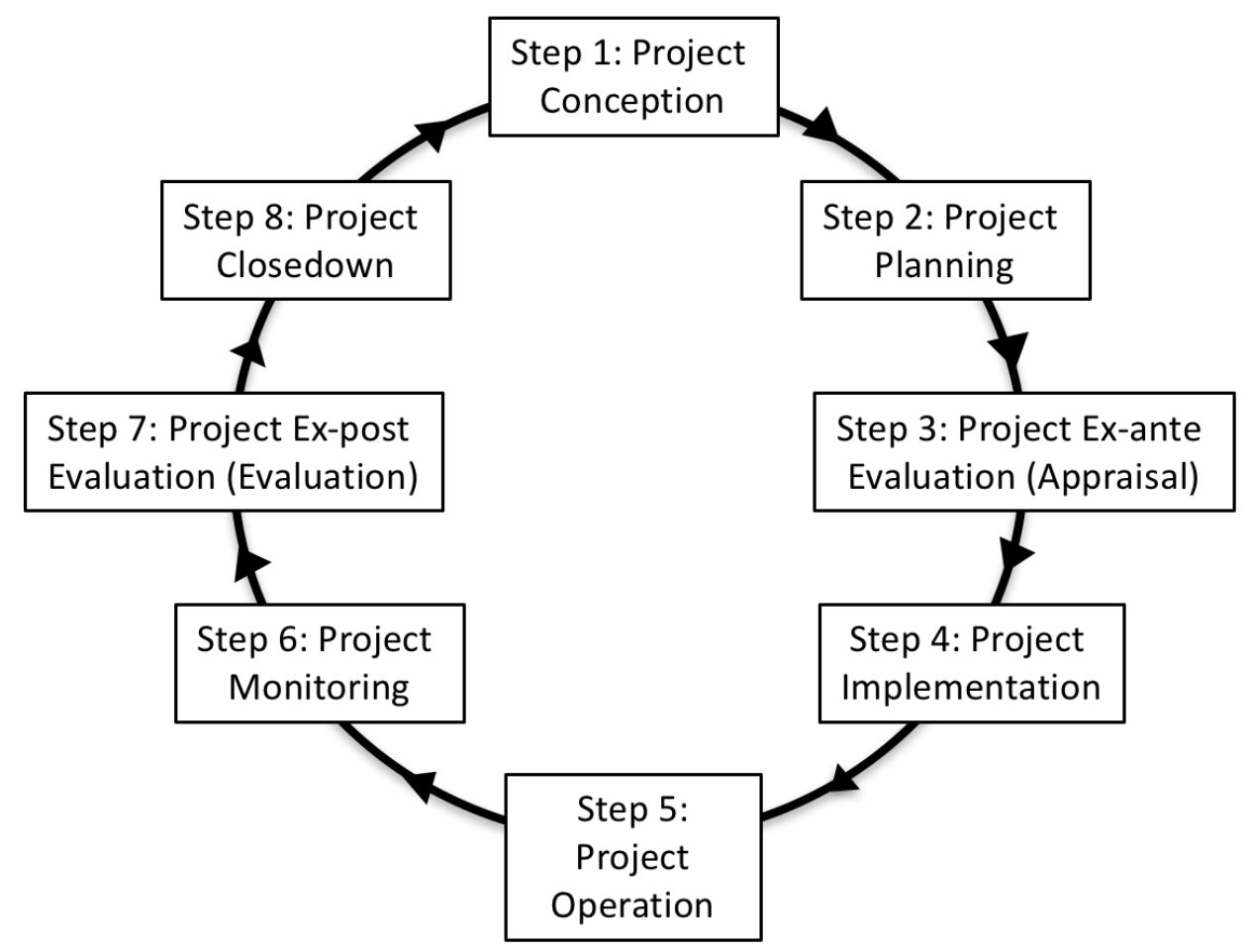

Figure 1: The Project Life Cycle (adapted from HM Treasury, 2003)

Drawing from Chapman and Ward's presentation of the project life cycle, during the first step (the conception phase), the rationale for intervention is identified. This phase typically entails an investigation of the different dimensions (economic, financial, political, social and technical) of the project's context for given agreed project boundaries. It also entails an identification of prevailing constraints and any major problems likely to affect the project's development, including those arising from the multiplicity of stakeholder interests and conflicting values that specified courses of actions (as response to perceived problems) should reflect. This is the period when the apparent need or desire for the project (in response to the identified challenges/problems the project is to address) is first considered by the sponsoring agent. This stage, however, remains, largely conceptual in that it lacks fine detail about the project's ultimate scope and operation.

The second step is the project planning phase during which actions are taken to determine the stakeholders affected by the project and the parties who are to bear responsibility for the intervention initiative. This phase specifies the desired objectives of the intervention, the values and criteria that the project should address in order to identify the full range of options that may be available to achieve these outcomes along with a first estimate of their respective costs.

Ex-ante evaluation - the third step of the project cycle - entails the ex-ante appraisal of the different alternative options for action assessed against the project's objectives and appraisal criteria. This phase is the focus of this publication overall. It traditionally firstly addresses concerns regarding 
financial and economic viability (e.g. by undertaking cost-benefit or value-for-money studies) and then examines other concerns. It should (and indeed is) increasingly extended/widened to include social, environmental and institutional aspects of the project (with varying degrees of success), as well as make recommendations about how the project is to be implemented.

The synthesis of the predicted project outcomes and impacts - as a basis on which project stakeholders/promoters make an informed judgment as to the viability of the intervention - can be accomplished in either of two ways (or both): Firstly, qualitatively, by assigning an informal judgment of the predicted impacts employing acknowledged values. Secondly, quantitatively, by applying mathematical modelling procedures designed to obtain a numerical score of likely outcomes and impacts by employing recognized standards and values. Project outcomes and impacts may be presented in a holistic and disaggregated form or combined together within a general index, such as a Cost Benefit Ratio (CBR). This phase may also include various forms of public consultation and/or participation exercises to better inform the appraisal exercise.

The phase that follows is the Implementation of the project (including the monitoring of its operation). By implication, this takes place once the option has been selected as the preferred 'solution' to the problem(s) and challenges identified at the outset. Project implementation commences when the project 'deliverers' (i.e., project consortium/joint venture parties, public sector works organizations etc.) are appointed, contracts are awarded and financial packages are agreed. It presumes business plans are approved, all necessary land acquisition have been made, construction work is undertaken/completed, mitigation measures are put in place and the operability of the project is tested and commissioned. During project operation, the project is brought into full use following the appointment of agencies responsible for its operation, management, maintenance and control and the provision of adequate funding.

Throughout project implementation and operation it is particularly important to collect data (monitoring) for ex-post evaluation. This is in effect a post-project implementation exercise which may include retrospective value-for-money assessments, audits, environmental impact studies, socio-economic impact studies and due diligence, on-going impact assessments, on-going monitoring of traffic flows etc. The role of ex-post evaluation is to enable users to learn from each completed project (through project feedback) so as to improve every following future appraisal and evaluation cycle. Project closure arises when it is decommissioned/demolished (as opposed to retrofitted for other purposes).

\subsubsection{Challenges for project appraisal}

Although appraisal is the explicit function of step 3 of the project lifecycle (as presented in Figure 1), it also plays an important role in other phases as pointed out by both McAllister (1982) and

Special 2016 Edition of The Journal of Research in Transportation Economics

'The Application of Policy-led Multi-Criteria Analysis to Megaproject Transport Infrastructure Appraisal' 
Paper 1: Presenting the Case for the Application of Multi-Criteria Analysis to Megaproject Infrastructure Appraisal Harry T. Dimitriou, E.John Ward and Marco Dean

Munda et al (1994). What needs to be appreciated as a prelude to project appraisal is that the project conception phase (step 1 ) identifies the problems and challenges to be addressed and that this in itself involves important value judgments. This is so because it determines the particular interests that will be served by the subsequent planning process. Also important to appreciate is that the tasks of setting project objectives in the planning phase (step 2) provide the context(s) for appraisal in the design of project alternatives which also involves major value-laden decisions. Exante appraisal (step 3) also plays an important role not only in arriving at the plan for execution in the implementation phase (step 4) but also in framing the subsequent monitoring of project outcomes and impacts (step 6) so that useful feedback on the entire project cycle can be provided for a full ex-post evaluation (in step 7).

As earlier indicated, although project appraisal has always been an intrinsic part of the decisionmaking process of the entire project life-cycle, more formal appraisal procedures began to emerge and be integrated within the overall plan making process only after the beginning of the twentieth century (Alexander, 2006a). Until then, the project planning process (i.e., all phases up to implementation) had been based upon survey and planning inquiries entailing a purely intuitive assessment of the merits and flaws of the different alternative project options (Olivera and Pinho, 2010). Aspirations and efforts to increase economic growth plus rising pressures to assure the proper allocation of public investment to maximize returns has done much to propel the popularity of CBA since the Second World War as a respected method to systematically compare the 'pros' (benefits) and 'cons' (costs) of a project and its options following their conversion into monetary terms. As alluded to below, strongly influenced by classical economics, CBA presupposes decision situations in which the decision-maker possesses complete knowledge of the problem(s) and challenges that the project is to address, and that on this basis he/she can select the best course of action to address the identified issues.

In the course of time, however, the subject coverage of the project appraisal decision-making process has become progressively more complicated, especially in the case of large-scale projects such as MTPs. Here, it has been concluded that complex decisions typically cannot (and should not) be simply made by relying on predominantly economic and financial perspectives. This is argued widely on the basis that such appraisal exercises inevitably involve trade-offs among multiple and conflicting objectives that include both economic and non-economic aims/outcomes of which only some can be satisfactorily monetised (Rosen, 1977; O'Connor et al., 1996; Adams, 1995; Sterling, 1998; Funtowicz et al., 1999). This very important point is perhaps best illustrated where project objectives look to the 'sustainable development' paradigm/vision ${ }^{3}$ as basis for assessing 'success' (see for example Pearce, 2008). Sustainable development in the context of infrastructure and city development requires awareness of the social, environmental and institutional dimensions of a

\footnotetext{
${ }^{3}$ Defined as development that meets the needs of the present without compromising the ability of future generations to meet their own needs (Brundtland, 1987).
}

Special 2016 Edition of The Journal of Research in Transportation Economics

'The Application of Policy-led Multi-Criteria Analysis to Megaproject Transport Infrastructure Appraisal' 
problem (and its resolutions), over and above the economic and financial (UN Habitat, 2013). It calls for a more careful consideration of the multiple project impacts and outcomes that a given course of action(s) could generate over the short, medium and long term - at global, regional and local levels simultaneously (see Figure 2). This broader perspective also calls for greater attention to be paid to the risks, opportunities and uncertainties that may be encountered at each planning period and level of action (Dimitriou et al, 2008; Véron-Okamoto and Sakamoto (2014).

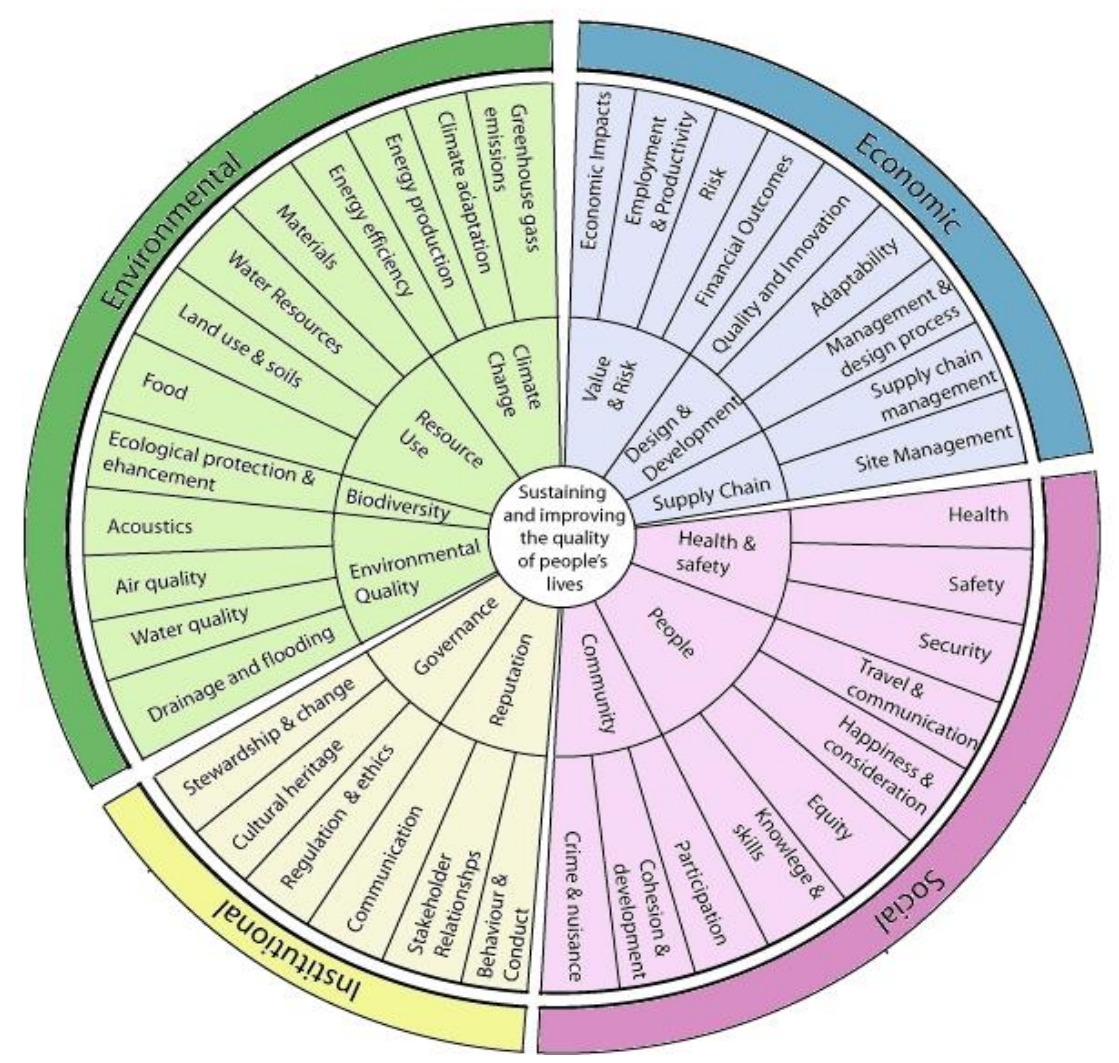

Figure 2: The four project dimension of sustainable development as conceived by the OMEGA Centre (Source: Dimitriou et al., 2010 - adapted from Pearce, 2008).

MTPs looking to service long-term planning horizons and long term sustainable development goals inevitably entail, by their very nature, a great number and variety of uncertainties (and opportunities). This is particularly the case in turbulent decision-making and policy contexts, on account of frequent changes (predictable and otherwise) in the financial, political, social, institutional and technical fields impacting on the project's future. Among other things, such challenges alter judgments regarding the relevance of project alternatives and the cost of options (Munda et al., 1994). Under such circumstances, together with time, budget and data availability constraints, as well as taking into account the prevailing habits, skills and limitations of the decisionmakers themselves, it is very difficult (near impossible) to arrive at straightforward and unambiguous 'solutions'. 
Added to the above perspective, it has been long-time convincingly argued (see Simon, 1976; Adams, 1995 and Sager, 2003) that complex infrastructure problems (and responses to them) are not adequately (let alone accurately) described by many/most rational decision-making models. This is concluded on the basis (as alluded to in the Editorial) that they (the project planning and appraisal methods) are frequently founded on the adoption of a concept of 'bounded rationality' that can ultimately ignore outside forces. As a result, as Munda et al., (1994) point out, decisionmakers attempt to arrive at a 'satisfying' solution rather than strive after the 'best' with suboptimum results.

The consequences of the adoption of such rigid and reductionist approaches to planning and appraisal are (as earlier attested) that the highly dynamic characteristic of the planning decisionmaking environment is frequently overlooked. This is especially the case when project appraisers (and the decision-makers they advise) focus on, or become pre-occupied with, principally only one of the project dimensions of the problems and challenges the project is intended to address. This consideration has, among other things, led to the development of numerous other appraisal methodologies over and above CBA, including MCA.

\subsection{Cost-Benefit Analysis}

\subsubsection{The rationale of $\mathrm{CBA}^{4}$}

As Alexander (2006a) affirms, Cost Benefit Analysis (CBA) was the earliest formal economic appraisal method applied to potential investments in major strategic projects. The technique was first institutionalized in the United State of America in the first half of the twentieth century, during the expansion of its public investment activities. It was adopted for the appraisal and evaluation of US road projects in the 1930's and US water projects in the 1950's (Pearce, 1998; Cameron, 2011). Since 1960s, under the impetus of pursuing more rational investments representing better 'value for money', the use of a standardised CBA spread world-wide, having been implemented in different sectors such as transport, urban planning and environmental management to name but a few (Hammond, 1966; Porter, 1995). In the UK, some of the earliest landmark applications of this method were to the appraisal of the M1 Motorway (Beesley, 1962) and later to the Victoria tube Line in London (Foster and Beesley, 1963).

CBA remains until this day the principal platform for traditional project appraisal practices globally in the infrastructure field, particularly for transport (see Banister and Berechman, 2000; Hayashi and

\footnotetext{
${ }^{4}$ This section and that which follows can be skipped-over by those experienced in the use of CBA. It is offered on account of the fact that the authors in their teaching have encountered a surprisingly large number of disciplines and professionals associated with infrastructure planning and delivery, such as spatial planners, project managers and civil engineers who have only the most cursory understanding of CBA and its principles, premises, strengths and limitations.
}

Special 2016 Edition of The Journal of Research in Transportation Economics

'The Application of Policy-led Multi-Criteria Analysis to Megaproject Transport Infrastructure Appraisal' 
Paper 1: Presenting the Case for the Application of Multi-Criteria Analysis to Megaproject Infrastructure Appraisal Harry T. Dimitriou, E.John Ward and Marco Dean

Morrisugi, 2000; Grant-Muller et al., 2001). In the UK, the Government's Green Book for the appraisal of major infrastructure projects recommends CBA as the preferred appraisal method (HM Treasury, 2003). More recently, in 2014, the European Commission published a manual for the standardized application of CBA to all investment projects. It was prepared for intended use by desk officers in the European Commission, civil servants in both Member States and Candidate Countries, as well as by staff of international financial institutions and consultants involved in the preparation or evaluation of investment projects.

In summary, CBA, through specific indicators, looks to provide a comparative overview of the possible pros (benefits) and cons (costs) of a given course of action. Its advocates purport that the method produces a valid indication of the economic contribution that a project will have for society as a whole, as well for project investors. They claim that CBA takes into account not only the real cash flow but also a wide range of economic, environmental and social impacts, both positive (benefits) and negative (costs), quantified in monetary terms adjusted for the value of money at the time at which they occur.

The basic CBA model is grounded in the principle of welfare economics which, in turn, grew out of the classical utilitarianism (Moroni, 2006; van Wee, 2012; Baujard, 2013), namely a moral and political philosophy whose origins are commonly traced back to Bentham (1789) who defined 'utility' as the intrinsic capacity of any object to produce satisfaction. While there is wide variation of utilitarian theories, they are united by their endorsement of the general fundamental ethical principle that an act is morally right if, and only if, that act maximizes the utility of a society (Moroni, 2006; Baujard, 2013).

The theory of Welfare Economics (see Dobb, 1970) suggests that the welfare of a society depends on the well-being (and 'utility's) of the transactions of individuals in a society. Building on this premise, CBA and its derivatives rely on the claimed ability of individuals to express their utility values of these transactions in monetary terms and use the 'willingness-to-pay' criterion as the basis for measuring both increases and decreases in utility. The maximum willingness-to-pay to secure a desired change is in this paradigm seen to represent a benefit; while the maximum willingness-topay to avoid an undesired change is deemed a cost (McAllister, 1982).

Adopting the concept of Pareto optimality (often referred to as the Pareto-principle), CBA assumes that a project is beneficial if it makes at least one person better off without making anyone else worse off. As a decision-making rule this is clearly far too restrictive, since there are both beneficiaries and sufferers for almost all projects (so-called 'win-win projects' are extremely rare).

\footnotetext{
${ }^{5}$ The justification of the pursuit of free trading and free competition on the premise that the resultant outcome represents a maximum of utility to the transacting parties involved was, according to Dobb (1970), afforded by Leon Walrus in 1874 and subsequently developed by Vilfredo Pareto with the assistance of Edgeworth's indifference curves.
}

Special 2016 Edition of The Journal of Research in Transportation Economics

'The Application of Policy-led Multi-Criteria Analysis to Megaproject Transport Infrastructure Appraisal' 
The strict application of the Pareto-principle has therefore been modified in conventional CBA applications by employing what is called the Hicks-Kaldor criterion (Kaldor, 1939; Hicks, 1939) which stipulates that a project is worthwhile if the calculus results in a net positive benefit, in other words, where the benefits outweigh the costs and there is a so-called 'potential Pareto improvement'. Some economist, however, see the Hicks-Kaldor decision rule as presenting serious deficiencies in addressing the actual impacts and distributional consequences of projects. Because no actual compensatory payments or transfers from project beneficiaries to sufferers need take place, and because of the possibility of marked differences in the utility functions of beneficiaries and sufferers occasioned by significant income and other distributional inequalities, a potential Pareto improvement is simply a numerical construct that by itself is not sufficient to ensure that decisions are equitable. What also needs to be considered is the willingness-to-pay compensation relative to the existing distribution of incomes to effect an 'actual Pareto improvement'.

\subsubsection{Procedures of CBA and its derivatives}

As earlier indicated CBA looks to the systematic estimation and conversion in monetary terms of all the positive and negative impacts of a project with the monetised value of a favourable impact termed a 'benefit,' while the monetised value of an adverse impact labelled a 'cost'. CBA is often referred to as Social Cost Benefit (SCBA) as the methodology concentrates on the effects, both good or bad, that a proposed project will have on society by considering the aggregated utility of transactions of its members measured in monetary terms identifiable through valuation techniques to derive willingness to pay. It should be pointed out that while the subject focus of SCBA exercises are intended to be more social, the underpinnings of the appraisal procedures employed are market values and economic efficiency concerns. Some authors (such as Snell, 1997) consider the reference to 'social' in SCBA should indicate a form of CBA which attempts to include important environmental and social factors that no market would reflect and therefore would not otherwise have been identified as having an effect on project's costs and benefits. This can be done it is claimed by incorporating subjective applications of value judgements for the non-monetised items. A classic example is to consider distributional issues via weighting factors.

A considerable amount of research and development in seeking to establish price and cost factors for CBA exercises has taken place over the decades, especially for transport infrastructure appraisal. They continue today with progress being made especially on the environmental front. The most common appraisal techniques currently employed for monetisation in CBA include (after Brent, 2006):

- The creation of surrogate markets, where market prices are used as an indirect reflection of, for example, environmental impacts (as in the case of the cost of insurance against the possible impact of a risk event).

Special 2016 Edition of The Journal of Research in Transportation Economics

'The Application of Policy-led Multi-Criteria Analysis to Megaproject Transport Infrastructure Appraisal' 
- Basing spending decisions on revealed behaviour, derived from an analysis of people's actual spending patterns (as in the case of higher payments for quicker travel indicating their value of time).

- Basing spending decisions on stated preferences derived from an analysis of people's responses to questions about spending in hypothetical situations.

Costs and benefits occurring at different times during the project lifecycle are opportunely discounted and presented on a common basis called 'net present values'. The formulas used to perform this calculation are shown below where a stated discount rate $(r)^{6}$ is used to make the adjustments to 'present value' of flows of project benefits and costs happening in different years (n) after the commencement of the project $(n=0)$.

$$
\begin{gathered}
\text { present value of Benefits } \mathrm{PV}(\mathrm{B})=\sum_{n=0}^{N} \frac{B_{(\text {year } n)}}{(1+r)^{n}} \\
\text { present value of Costs } \mathrm{PV}(\mathrm{C})=\sum_{n=0}^{N} \frac{C_{(\text {year } n)}}{(1+r)^{n}}
\end{gathered}
$$

This valuation in essence suggests that, taking into account interest and inflation, it is better to have $\$ 1$ in one's pocket today rather than in a few years' time ahead. So that the discounted present value of $\$ 1$ in 15 years using an 8 percent discount rate, for example, would be $\$ 0.315$.

The question of which discount rate is appropriate is one of the most debated issues in CBA. The use of high or low discounted rates is variously defended using a number of arguments depending on context and circumstances. The choice of a suitable ' $r$ ' value is associated with efforts and aspirations to achieve a balance in outcomes between present and future generations. A high rate, for example, is likely to reject investments, allowing a higher proportion of resources being spent on consumption by present generations. A low discount rate, on the other hand, is likely to facilitate the implementation of more projects for future generations. High discount rates, furthermore, strongly reduce the weight of long term benefits and costs (see Figure 3). Consequently, especially if important costs and benefits occur in the long term (more than say 30 years), as in the case of major infrastructure projects, the discount rate may have a large impact on the social cost benefit outcomes (Koopmans and Rietveld, 2013). By illustration, the recommended discounted rate for major transport projects annually in the UK is six percent, seven percent in the USA and Australia, eight percent in Norway and 10 percent in Canada (Næss, 2006).

${ }^{6}$ This can be defined as rate at which an individual or group values the present compared to the future. 


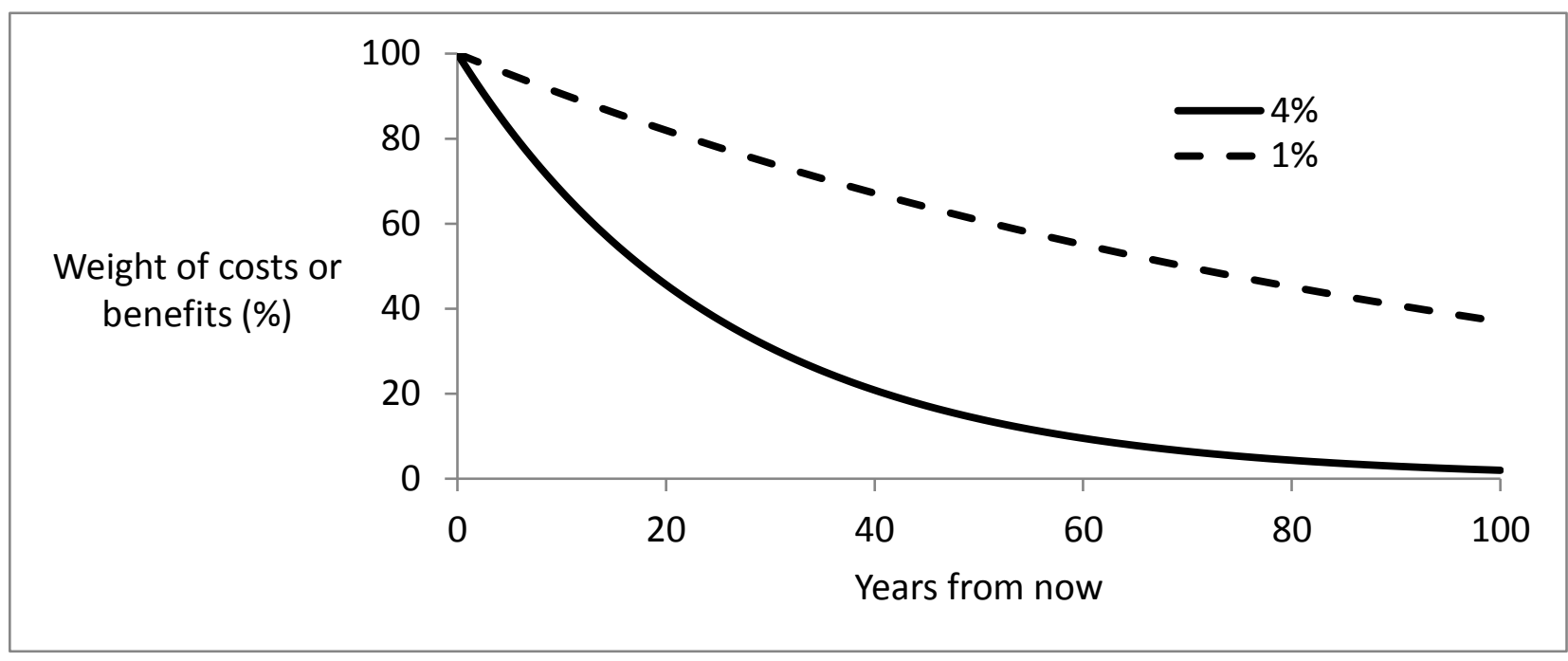

Figure 3: Impact of the discount rate of the benefits occurring in different years (Source: Koopmans and Rietveld, 2013)

Accordingly, in SCBA, a broader range of benefits and costs (including the mitigation of risks) are ultimately expressed in monetary terms and adjusted for the value of money at the time at which they occur. Annual costs of risky events such as natural hazards which may damage a project are estimated in probabilistic terms. The final results of CBA are often presented in summarizing indicators with the main ones employed being the Net Present Value (NPV). This is obtained by subtracting the sum of the discounted costs from the sum of the discounted benefits, the BenefitCost ratio (BCR) derived by dividing the sum of the discounted costs into the sum of the discounted benefits (expressed by the following formulae).

$$
\begin{gathered}
\text { Net Present Value (NPV) }=P V(B)-P V(C) \\
\text { Benefits - Costs Ratio } \mathrm{BCR}=\frac{P V(B)}{P V(C)}
\end{gathered}
$$

There is a basic relation here between NPV and BCR: when NPV is positive (i.e., when benefits are greater than costs), the BCR exceeds the value of 1 . Vice versa, when the NPV is negative, the BCR falls between 0 and 1 . In addition, another index is employed that represents the Internal Rate of Return (IRR) of the project's investment. This is calculated by estimating the interest rate at which the sum of the discounted benefits becomes equal to the sum of the discounted costs. In other words, the situation when the IRR is the value of $r$ for which NPV $=0$ and $B C R=1$. This is calculated by employing the following formulae:

$$
\text { Internal Rate of Return }(\text { IRR }) \rightarrow P V(B)=P V(C) \rightarrow \sum_{n=0}^{N} \frac{B_{(\text {year } n)}}{(1+r)^{n}}=\sum_{n=0}^{N} \frac{C_{(\text {year } n)}}{(1+r)^{n}} \rightarrow r=\text { ? }
$$


Uncertainty about the estimates of costs and benefits is addressed by means of employing sensitivity tests (typically, probability analyses of different situations arising). Once the sensitivity analysis has been carried out using the best estimate of all and the different indexes have been used to better inform the assessment exercise, the parameters of the analysis are varied, generally oneby-one, in an effort to ascertain the extent to which the economic indicators are subsequently altered. The spreadsheet to calculate the summary results of these procedures, namely BCR, NPV and IRR estimates, need to be set up in a fashion similar to the format displayed below in Figure 4 to facilitate the arithmetic. The example in Figure 4 consists of a hypothetical three-year transport project for which a discount rate equal to 7 percent has been assumed. The NPV suggests that society is around one and a half million dollars better off after the implementation of the project. The BCR indicates that for every dollar of capital expended on the project, society gains $\$ 1.4$.

\begin{tabular}{|c|c|c|c|c|}
\hline & \multicolumn{4}{|c|}{ Years (0 to $n)$} \\
\hline & $\begin{array}{r}0 \\
(\$ m)\end{array}$ & $\begin{array}{r}1 \\
(\$ m)\end{array}$ & $\begin{array}{r}2 \\
(\$ m)\end{array}$ & $\begin{array}{r}n \\
(\$ m)\end{array}$ \\
\hline \multicolumn{5}{|l|}{ Benefits } \\
\hline - Travel time savings & 0.000 & 2.000 & 2.600 & $\ldots$ \\
\hline - Vehicle operating cost savings & 0.000 & 0.500 & 1.000 & $\ldots$ \\
\hline - Reduced green house gas emissions & 0.000 & 0.250 & 0.500 & $\ldots$ \\
\hline - Reduced pollution to nearby waterway & 0.000 & 0.100 & 0.150 & $\ldots$ \\
\hline Total benefits & 0.000 & 2.850 & 4.250 & $\ldots$ \\
\hline \multicolumn{5}{|l|}{ Costs } \\
\hline - Capital investment & 4.000 & 0.000 & 0.000 & $\ldots$ \\
\hline - Recurrent/operating & 0.000 & 0.500 & 0.500 & $\ldots$ \\
\hline - Externalities (noise intrusion) & 0.000 & 0.010 & 0.010 & $\ldots$ \\
\hline Total costs & 4.000 & 0.510 & 0.510 & $\ldots$ \\
\hline Present value of total benefits & 0.000 & 2.664 & 3.712 & $\ldots$ \\
\hline Present value of capital costs & 4.000 & 0.000 & 0.000 & $\ldots$ \\
\hline Present value of non-capital costs & 0.000 & 0.477 & 0.445 & ... \\
\hline Benefit-cost ratio (BCR) & 1.4 & & & \\
\hline Net present value (NPV) & 1.5 & $\$ m$ & & \\
\hline Discount rate used ( $r$ ) & 7.00 & $\%$ & & \\
\hline
\end{tabular}

Figure 4: Example of CBA for a three-year transport project (Source: DOT, 2010) 
This appraisal method can be used essentially for two types of decision situations: for accept-reject decision or ranking different alternative course of actions (either technically mutually exclusive or mutually independent projects). In the first case, the standard CBA criterion for accepting or rejecting a proposed public action is the guarantee that the benefits would exceed costs and consequently that NPV would be positive (and BCR would be grater that 1 ). In the case of choosing a course of action between several mutually independent projects within a financially unconstrained context, the CBA criterion for identifying the 'preferred' project is the maximization of the benefits as expressed by the NPV. For a project ranking problem, where limited financial resources are an issue, the CBR index is probably more appropriate to determine value for money.

\subsubsection{Critical review of CBA and its derivatives}

According to a host of authors (see for example Leonard and Zeckhauser, 1983; Vining and Weimer, 1992; Van Wee and Tavasszy, 2008; Van Wee and Rietveld, 2013) CBA and its derivatives purportedly possess numerous important assets that make them very useful project appraisal tools for infrastructure developments. Among other things, they claim that CBA and its derivatives:

- are based on an established theory that has been scrutinized and debated by many economists during their lengthy evolution and that they have been suitably adjusted to meet many cited theoretical and operational shortcomings (see later discussion);

- represent a relatively straightforward and 'neutral' appraisal method to assess the opportunities and costs alike for undertaking a project;

- employ appraisal impact categories and measurement units (predominantly money-based) that are understandable to decision-makers and representatives of the public alike (including government representatives where they are not stakeholders);

- rely on relatively well-known assumptions about most costs and benefits for different categories of projects and that these are supported by an extensive body of literature on the application of CBA covering a wide variety of problems that may be used as a basis for deriving the impacts of future projects; and

- capture in the final judgment the values of all people rather than a selected few.

Set against the above proclaimed strengths, a number of assumptions underlying CBA and its derivatives are strongly challenged by a growing number of parties (economists and non-economists alike), many of them with involvement in infrastructure and transport developments (see for example, Nijkamp and van Delft, 1977; Heinzering and Ackerman, 2002). These reservations may be summarized as follows under a set of stated questionable assumptions employed by CBA:

- CBA works best in a regime of a perfectly competitive market: This claim is misplaced because the infrastructure market has a large number of 'buyers' and 'sellers', most of whom are not in a position to dominate and/or influence the price of the products they buy or sell. In such 
conditions all consumers and producers are assumed to have perfect knowledge of price, utility, quality and production methods of products. The challenge here is that these conditions are hardly ever encountered in practice on account of the fact that there are monopolies and governments (especially in the infrastructure field) whose interventions distort the market. These circumstances, thus make it very difficult (if not impossible) to calculate the market prices of some of the items/aspects appraised; especially social, amenity and environmental impacts of a project. This is made more problematic by the complexity of many of the challenges confronted by infrastructure projects (MTPs in particular) and the lack of transparency in the assumptions inherent in the valuation of different types of impacts. These conditions make the calculations impossible to penetrate for people other than a narrow group of experts. This leads to opacity in decision-making and potentially to the manipulation of results. Reinforced by the non-participatory nature of the CBA process, these circumstances are likely to increase controversies in the decision-making process which can delay projects and ultimately add to their cost (McAllister, 1982; Heinzering and Ackerman, 2002; Koopmans and Rietveld, 2013).

- The best way to appraise environmental and social factors in CBA is to express them in a common unit of measurement giving them monetary values: This claim is challengeable on the grounds that this can be legitimately achieved through the creation of artificial prices for such benefits and costs. The challenge here is that in reality, this one dimensional appraisal unit is simply unable to represent adequately the different impacts of a project (be it an infrastructure scheme or another project). Even where SCBA is employed, because the factors considered are essentially confined to those that can easily be translated into monetary terms, the appraisal method is seen to essentially to be biased toward the premise of 'what cannot be monetized is not important' (Vasconcellos, 2003). Furthermore, the process of reducing life, health, amenity and elements of the natural environment to monetary values can in certain/most societies be considered not only immoral but additionally inherently inaccurate (Adams, 1995). This is so, since no finite amount of money is seen in these societies to compensate a person (or community) for losses associated with death, especially of loved ones (Heinzerling and Ackerman, 2002 and Hansson, 2007).

- Economic efficiency is the driving political policy objective of CBA: The justification for discounting future consequences of project outcomes in appraisal exercises entails the implicit adoption of a decision-making model characterized by a history of steady economic growth and an absence of any catastrophic events or irreversible harm. This questionable assertion is done by reducing benefits and costs over many decades to almost zero according to the most commonly used discount rates. The premise here is that nature is assumed to be almost totally replaceable with human-capital and that there is no real need for precautionary investment in environmental protection. The challenge is that while discounting any such harm may be useful from a financial point of view, it cannot reasonably be used to discriminate between present 
and future generations. In these terms, CBA is inherently flawed as an appraisal tool. This is especially so where (and when) sustainability concerns as defined by the Brundtland Commission need to be addressed, particularly issues of inter-generational sustainability and equity (Eckstein, 1958; Baumol, 1968; Van Wee and Rietveld, 2013).

- The social value of an impact of a given project in CBA is premised on the total population's willingness to pay for obtaining or avoiding this impact: The challenge here is that in reality CBA often has difficulty in defining the full spectrum of who exactly is affected by the proposed development project since society consists of different individuals, often possessing very different priorities. People who hold strong environmental and humanistic values, for example, place less emphasis on making high incomes. Thus, their willingness-to-pay is lower than other people. Additionally, affluent people typically have a higher willingness-to-pay threshold than poor people. These realities undermine the CBA premise that the value of something 'for society' should (and can) be reducible to an aggregate preference since in this way the views and wishes of certain parties are discriminated against. As earlier indicated, furthermore, methodologies to include distributional effects are also not rigorously applied in most CBA appraisal guidelines. Thus, even on account of the absence real compensation measures in the model, CBA may tend to pursue economic efficiency goals while simultaneously ignoring and reinforcing patterns of social inequalities (Heinzering and Ackerman, 2002; Oka, 2003; Rietveld, 2009).

- CBA views a population, its society and individuals in terms of consumer units: The challenge here is that people are not concerned only about themselves but also about the risks (of project outcomes) to their families, communities and society as a whole. By ignoring these facts it is alleged that CBA considers citizens as mere selfish consumers and nothing more. In these terms, CBA cannot represent political preferences or clear policy objectives that are different from those which can be measured by consumers' preference. In this sense, CBA clearly fails to address the collective choice presented to society by most social, amenity and environmental problems. This is inconsistent with international environmental policy directives and guidance that aims, for example in the case of a road infrastructure project, to reduce motorised mobility that pollutes and look to alternative more green options. An additional argument against the consumer-based perspective offered by CBA and its derivatives is that it may be seen to promote a deregulated neo-liberal agenda under the cover of scientific objectivity where welfare costs and benefits not suited to market place analysis are devalued, mis-valued or worse still, omitted. In the case of wider policy objectives, CBA can thus be of little assistance in the ranking of alternatives as it omits consideration of non-monetary concerns (Sen, 1979; Heinzering and Ackerman, 2002; Næss, 2006; Van Wee and Rietveld, 2013).

- $\quad$ CBA is an appraisal tool that is equally as effective irrespective of the scale and complexity of the project to which it is applied: This premise is challenged by many infrastructure appraisal 
specialists, including Hausman and McPherson (2006) and van Wee (2011). They argue that while CBA appears to be adequate for small and uncomplicated projects where uncertainties are limited, for complex decision-making problems confronted by large-scale infrastructure projects such as MTPs, alternative appraisal methods to CBA are required or need to be added to CBA. The justification for this (echoed elsewhere in this paper) is that CBA seems to be too static and too narrow an appraisal tool to capture adequately the dynamics of decision-making typically associated with megaprojects across their lifespan. The relationships of mutual interdependencies that major infrastructures frequently possess (see The systems centre, 2013), and the long-term, multiple and wide impacts that mega-projects usually produce on the traversed territories and served communities further compromise the viability of CBA exercises for major infrastructure projects, including MTPs (Rothengatter, 2008).

\subsection{Broader-based project appraisal methods}

\subsubsection{Background and history}

Concerns of the kind cited above have for some time now encouraged a search for the development of broader-based appraisal methods. From the late 1960s to the end of the 1980s and perhaps into the early 1990s, a number of alternative project appraisal techniques were developed and proposed in an attempt to address many of the limitations of CBA. These by and large, represented a reaction to what some parties believed was the rigid economic reasoning underlying CBA (Sager, 2003). Amongst the most significant of these new methods were:

- Cost-Effectiveness Analysis (CEA) and its derivative Program Planning Budgeting Systems (PPBS);

- the Planning Balance Sheet (PBS);

- the Goal Achievement Matrix (GAM); and

- Multi-Criteria Analysis (MCA).

All go beyond the pure monetary appraisal of project appraisal decision-making. While it is probably the case that these new techniques are essentially seen by the more conservative as methods that inform (and thus complement) CBA rather than be a substitute for it, the MCA framework and attendant processes (see later discussion) offer both informing/complementarity options. They also offer a more holistic framing of project appraisal within which most/all other appraisal methods can be potentially used where and when considered appropriate (see later discussion). This allows both non-monetary and monetary attributes to be assessed within the same frame without rejecting CBA and has considerable potential for application to mega infrastructure projects and complex urban projects as risk and opportunity registers that usefully complement more traditional appraisal (OMEGA Centre, 2014). Sections 1.4.2-1.4.4 below offers a review of these broader-based project appraisal techniques as a prelude to presenting in the concluding sections the case for the

Special 2016 Edition of The Journal of Research in Transportation Economics

'The Application of Policy-led Multi-Criteria Analysis to Megaproject Transport Infrastructure Appraisal' 
Paper 1: Presenting the Case for the Application of Multi-Criteria Analysis to Megaproject Infrastructure Appraisal Harry T. Dimitriou, E.John Ward and Marco Dean

application of policy-led MCA to megaproject infrastructure appraisal. This is further elaborated on and illustrated in the context of MTPs in the following two papers offered by this monograph.

\subsubsection{Cost-effectiveness Analysis (CEA)}

CEA aims at identifying which project (or programme of projects) can achieve particular objectives at the lowest cost (Levin, 1995). The method was first developed in the 1950s by the US Department of Defence as a device for adjudicating on the most convenient weapons systems of the various branches of the armed services (Hitch and McKean, 1960). By the 1960s it had become widely used as a tool for analysing the efficiency of alternative government projects and programmes of projects outside of the military (including major infrastructure projects), culminating in the development of Planning, Programming Budgeting Systems (PPBS) which sought to appraise projects across both programmes and sectors (see US Congress, 1969).

CEA is closely related to CBA in that both expect positive and negative impacts of a project to be quantifiable and seek to compare their relative merits. It should be noted, however, that while the costs of a project in CEA are estimated in monetary terms and discounted to the present value analogously to CBA, the estimation of benefits in CEA is not presented in monetary terms. These are instead measured in proxy terms by different physical units, such as: travel time savings, reductions in accident levels and/ or increases in accessibility to given locations (in the case of transport projects). For health programmes and projects, the benefits may be measured in terms of increases in the early detection rates of particular illnesses or in terms of possible decreased mortality rates against a given medical pathology. Measures of effectiveness could also be based on (or derived from) an attitude survey as is sometimes the case in CBA. More often, however, CEA tends to proceed with the employment of indicators of a project's effectiveness chosen by experts (through, for example, Delphi exercises) which is cheaper and quicker than eliciting attitudes and values from individuals by means of interview surveys (Pearce et al., 2006).

In these terms, given the presentation of a problem to be solved and having established the most useful and pertinent dimensions and measures of effectiveness, CEA allows the comparison of different project options by addressing that problem on the basis of a Cost-Effectiveness Ratio (CER) represented by the following formulae:

$$
\text { Cost-Effectiveness Ratio }(C E R)=\frac{P V(C)}{P V(E)}
$$

Where:

$\mathrm{PV}(\mathrm{C})$ is the costs of the intervention

$\mathrm{PV}(\mathrm{E})$ is the effects produced by the intervention

Special 2016 Edition of The Journal of Research in Transportation Economics

'The Application of Policy-led Multi-Criteria Analysis to Megaproject Transport Infrastructure Appraisal' 
Employing the above formulae, an option with a CER equal to ' 1 ' (or more) is seen as 'economically justifiable' as the base case of the 'do-nothing' or 'do-minimum' option. A value in excess of ' 1 ' suggests that the option is not viable relative to the base case. Hence, a project with the lowest CER is one whose implementation would be seen to be more cost-effective than others.

As Rogers and Duffy (2012) indicate, it is also possible to use more than the ' 1 ' measure of effectiveness in CER exercises. This is done by means of using a linear scoring function, where different weights are ascribed to different measures of effectiveness so as to arrive at a 'Global Effectiveness Score' that successively has to be set against the discounted cost. The Global Effectiveness Score for a given option, where $\mathrm{j}$ measures of effectiveness have been identified, can be represented by the following formulae:

$$
\text { Global Effectiveness Score }=\sum_{j} W j X j
$$

Where:

$W j$ is the weight placed on the $j^{\text {th }}$ measure of effectiveness, $\mathrm{Xj}$ is the score for the $\mathrm{j}^{\text {th }}$ measure of effectiveness for the given option.

On the basis of the above, CEA can be considered an important variant of CBA which has the potential to be particularly useful in comparing different competing course of actions whose benefits are difficult to measure in monetary terms alone. On the other hand, since it retains practically half of the basic structure of CBA, it also presents many of the same shortcomings of CBA.

\subsubsection{Planning Balance Sheet (PBS)}

PBS was originally developed in 1956 by Nathaniel Lichfield as an ex-ante evaluation (appraisal) technique (Sager, 2003). It was developed as a means to overcome some of the earlier cited drawbacks of CBA, in particular the difficulty of assigning meaningful monetary values to project costs and benefits, and establishing the extent to which different stakeholders may be affected by a project (McAllister, 1982). This methodology was initially applied in its most basic form in the late 1950s and early/mid-1960s (Lichfield, 1956, 1960 and 1966) and elaborated more fully as Planning Balance Sheet Analysis (BPSA) in 1970. It was subsequently developed and renamed the 'Community Impact Evaluation' (CIE) in the 1980s and beyond (Lichfield, 1985, 1994 and 1996). For descriptions of this appraisal method and its development, see Rogers and Duffy (2012) and Lichfield's own publications (see references at the rear of this paper).

In PBS two or more alternative project proposals are compared according to the impacts they bring to the community. Such impacts, referred to as 'transactions' (with outcomes that have impact) are categorized according to the groups which produce them ('producers') or groups which receive them ('consumers'). With reference to the Figure 5, for instance, in which two competing 
Paper 1: Presenting the Case for the Application of Multi-Criteria Analysis to Megaproject Infrastructure Appraisal Harry T. Dimitriou, E.John Ward and Marco Dean

plans/projects ( $A$ and $B$ ) are considered, the 'producers' are expressed as $X, Y$, and $Z$, while the consumers are identified as $X^{1}, Y^{1}$ and $Z^{1}$. The costs and the benefits that would accrue to these various parties are recorded as capital items or reoccurring costs - expressed in monetary terms (in the case of a typical market transaction) or non-monetary terms (in the case of aspects for which market values are not readily identified).

In the same exercise (shown in Figure 5), all projected estimates are discounted to their present value, akin to a CBA exercise. Where, however, the magnitude of a measurable impact cannot be satisfactorily estimated either a $\$$ or $\mathrm{M}$ symbol are assigned, along with a brief description (text) to inform the appraiser/decision-maker that a monetized or a quantitative (but non-monetised) outcome is expected as a result of the project (plan) implementation. Conversely, if expected impact of the project is an intangible, an ' $i$ ' is assigned to the relevant aspect and a brief verbal note is prepared/recorded/provided explaining the qualitative dimensions. A dash (-) in a cell, in the same exercise, indicates that no cost or benefit of that type would affect the dimension in question in the event the project (plan) is executed. The benefits and costs are then subsequently annualised and totalled for each of the groups. The reduction, aggregation and comparison of the various costs and benefits accruing to each dimension allow, over a number of iterations, to make a decision about the course of action which would be deemed more appropriate to maximize the benefits within the community. Hence, differently from CBA, in PBS the decision-makers are obliged to explicitly (and transparently) acknowledge subjective judgments when making/taking the final appraisal decision (Massam, 1980).

\begin{tabular}{|c|c|c|c|c|c|c|c|c|c|}
\hline \multirow{2}{*}{ Producer } & \multicolumn{2}{|l|}{ Plan $A$} & \multicolumn{2}{|l|}{ Plan $B$} & \multirow{2}{*}{ Consumer } & \multicolumn{2}{|l|}{$\operatorname{Plan} A$} & \multicolumn{2}{|l|}{ Plan $B$} \\
\hline & Benefit & Cost & Benefit & Cost & & Benefit & Cost & Benefit & Cost \\
\hline 1 & & & & & 2 & & & & \\
\hline 3 & & & & & 4 & & & & \\
\hline 5 & & & & & 6 & & & & \\
\hline 7 & & & & & 8 & & & & \\
\hline & & & & & & & & & \\
\hline
\end{tabular}

Figure 5: Example of Planning Balance Sheet of development for the comparison of two plans (Source: McAlister Hill, 1982)

On the basis of the above, it may be argued that PBS offers two principal advantages over CBA (after McAllister,1982): 
- Firstly, it establishes a formal procedure for recording non-monetary and intangible impacts alongside monetised ones and thus heightens the importance of the former against the latter in the appraisal.

- Secondly, it provides important information concerning distributional and equity impacts of a project which may be useful when undertaking mitigation measures.

On the other hand, being a variant of CBA, PBS again shares most of the weaknesses of the former. These include the disadvantage that monetised impacts may tend to prevail over intangibles and other non-monetary effects in the final judgment, and the issues provoked by discounting future consequences of a project. When project impacts need to be estimated for several groups within society, the time and costs for assessing a project by means of PBS can be much higher than CBA. This can make PBS unattractive to project promoters who in reality frequently value short term concerns related to the speed and cost of project delivery much above longer term outcomes.

\subsubsection{Goal achievement matrix (GAM)}

A second celebrated project ex-ante evaluation (appraisal) technique originally developed in the mid-1960s that looked at providing a broader perspective than offered by the more traditional monetised based CBA appraisal methods is the Goal-Achievement Matrix (GAM). Conceived by Morris Hill (1966 and 1968), this represented an attempt to overcome both some of the shortcoming of PBS and the already acknowledged limits of CBA. Notwithstanding its advantages, Hill (ibid, 1968) argued that PBS failed to recognize the fact that since projects have multiple goals, and that their costs and benefits can only be compared if they related to a common set of objectives. He further argued that PBS does not allow decision-makers to understand whether the identified costs and benefits are relevant for inclusion in the balance sheet of development since different project impacts have different levels of relevance for the various stakeholders. Sager (2003) claims that the debate between Hill and Lichfield represented the most significant exchange of informed opinion on the design and development of project appraisal up to Hill's death in 1986 if not well after. ${ }^{7}$

As in Lichfield's PBS methodology, Hill's GAM approach acknowledges that project impacts are linked to different project stakeholders and that they may be categorized as monetary, nonmonetary or intangibles. In the case of GAM, it is accepted that different objectives within the same project need to be identified and weighted to express their relative level of importance (McAllister, 1982). In the case of an engineering project, for instance, Hill and Schecheter (1971) identified the following set of ideals that could be used to derive appraisal objectives:

- to contribute to enhanced physical and mental health,

- to generate additional enjoyment,

\footnotetext{
${ }^{7}$ Lichfield passed away in 2009.

Special 2016 Edition of The Journal of Research in Transportation Economics

'The Application of Policy-led Multi-Criteria Analysis to Megaproject Transport Infrastructure Appraisal' 
- to create more equity,

- to enhance economic welfare,

- to contribute to social stability, and

- to assist in the achievement of ecological balance.

GAM employs a double set of weights to reflect both the relative importance of each objective to the whole community (overall weighting) and the incidence of costs and benefits associated with any objective (relative weighting). Given a project to be appraised against a set of planning objectives or goals (1, 2 \& 3 in Figure 6$)$ the assessment of that project using the GAM methodology implies the need to identify impact categories and the need to formulate in advance relative and overall weights. According to Hill (1968), the estimation of the relative weighting of the objectives should be derived (by the analyst) from consultation processes, together with the sampling of public opinion and behavioural observations. He considers the weighting procedures the key to GAM, pointing out that this appraisal methodology can turn out to be of limited value if weights cannot be objectively determined.

\begin{tabular}{|c|c|c|c|c|c|c|c|c|c|}
\hline Goal description & Goal 1 & & & Goal 2 & & & Goal 3 & & \\
\hline Value weight & 2 & & & 3 & & & 5 & & \\
\hline \multirow[b]{2}{*}{ Incidence } & \multirow{2}{*}{$\begin{array}{l}\text { Value } \\
\text { weight }\end{array}$} & \multicolumn{2}{|l|}{ Impacts } & \multirow{2}{*}{$\begin{array}{l}\text { Value } \\
\text { weight }\end{array}$} & \multicolumn{2}{|l|}{ Impacts } & \multirow{2}{*}{$\begin{array}{l}\text { Value } \\
\text { weight }\end{array}$} & \multicolumn{2}{|l|}{ Impacts } \\
\hline & & Benefits & Costs & & Benefits & Costs & & Benefits & Costs \\
\hline Group a & 1 & A & D & 5 & $\mathrm{E}$ & - & 1 & & $\mathbf{N}$ \\
\hline Group b & 3 & $\mathrm{H}$ & & 4 & - & $\mathbf{R}$ & 2 & & - \\
\hline Group c & 1 & L & $\mathbf{J}$ & 3 & - & $\mathrm{S}$ & 3 & M & - \\
\hline Group d & 2 & - & & $2\}$ & $\mathrm{T}$ & - & 4 & & - \\
\hline \multirow[t]{2}{*}{ Group e } & 1 & - & $\mathbf{K}$ & $1\}$ & & $\mathrm{U}$ & 5 & & $\mathbf{P}$ \\
\hline & & $\Sigma$ & $\Sigma$ & & & & & $\Sigma$ & $\Sigma$ \\
\hline
\end{tabular}

Figure 6: Example of Goal Achievement Matrix carried out for one project (Source: McAlister , 1982)

As in the case of PBS, the costs and benefits occurring to the different stakeholders are recorded in a matrix as money, other quantified units or intangible impacts. In Figure 6 the capital letters represent estimated impacts. The brackets indicate where an impact applies to several groups combined. A blank implies that no impact is expected, and a dash indicates that the estimated impact is negligible. Uncertainty concerning anticipated consequences is considered by probability formulation as in CBA. Future impacts are discounted to present value, using conventional CBA 
Paper 1: Presenting the Case for the Application of Multi-Criteria Analysis to Megaproject Infrastructure Appraisal Harry T. Dimitriou, E.John Ward and Marco Dean

procedures. The summation sign at the bottom of a column indicates that all the impacts for the corresponding goal can be quantified and therefore can be totalled (McAllister, 1982).

The measurement of the level to which each objective is met by the project is carried out through the use of transformation functions which facilitate the aggregation of different outcomes on a single scale. These indices are then multiplied for the respective weights to derive a grand score of goal-achievements (Hill, 1968). The preferred plan from amongst the competing schemes is the one with the highest overall index. However, since the effects of intangibles have to be accounted, even with the adoption of GAM the final decision involves subjective evaluation by the decision-maker (Massam, 1980).

McAllister (1982) argues that GAM and PBS are superior to CBA on account of the fact that both depict a systematic method for recording non-monetary and intangible project impacts, alongside monetised ones and account for a projects equity effects. Moreover, he further claims that GAM also enjoys some advantages over PBS: for while in PBS the impact categories and stakeholders are identified according to the 'transactions' generated by the project, in GAM the appraiser is free to select the objectives and community groups to be used in assessing equity effects.

Notwithstanding the above advantages of GAM, Hill's method still contains some of the same weaknesses of CBA. For example, as in the case of CBA, only quantified project impacts can be included in the grand index of goals achievement. In practical terms this means that there is a serious risk that intangibles are not accounted for properly in the formulation of the final decision. Moreover, since a separate matrix of impact information is required for each alternative being appraised, GAM is clearly very demanding of detailed impact information compared to CBA, CEA and perhaps also to PBS.

\subsubsection{Multi-Criteria Analysis (MCA)}

Of the above, GAM more than CEA and PBS, depicts the first step towards the development of MCA in project appraisal (Rogers and Duffy, 2012). As the following paper explains more fully, MCA (sometimes referred to as Multi-Criteria Decision Analysis - MCDA) has been an active area of research since the 1970s in response to the increasing demand for project appraisal methodologies seeking to address broader aspects than those strictly measurable via monetisation and constituting the direct financial and economic effects of projects.

MCA methods (as earlier explained) involve structures and rules sets which allow monetary and non-monetary, quantitative and qualitative criteria to be considered in complex decision-making (Vincke, 1992; Mackie and Preston, 1998). Advocates of the approach claim thereby to overcome many problems associated with efforts to monetise all dimensions under appraisal. Specifically,

Special 2016 Edition of The Journal of Research in Transportation Economics

'The Application of Policy-led Multi-Criteria Analysis to Megaproject Transport Infrastructure Appraisal' 
MCA appraises a given project against a set of different objectives which have been identified by stakeholders for which a set of measurable and non-measurable criteria have been established to assess the extent to which these objectives are achieved (Nijkamp and van Delft, 1977). It is important to point out, however, that MCA can incorporate CBA appraisals within its framework (as deemed appropriate), as well as other types of appraisal such as Environmental Impact Analysis (EIA). Depicting a heterogeneous appraisal method MCA especially assists decision makers faced with making numerous and conflicting decisions/judgments (De Brucker et al., 1998). It also helps better frame the scope of the project appraisal exercise in a manner that incorporates key stakeholder interests and concerns they might involve. In this sense, MCA exercises are thus designed to present a more complete picture of the implications of project outcomes and outputs across multiple fields of impact searching in the process for the most appropriate trade-offs between different key objectives (OMEGA Centre, 2010).

An underlying premise of this paper, indeed the entire publication, is that in the context of megaproject decision-making, having an understanding of the problems associated with the choice and prioritisation of appraisal criteria employed by different stakeholders - together with the comprehension of different kinds of costs and benefits considered - offers a sound basis for high added-value shared problem analysis. A further premise is that MCA, especially an appraisal approach led by policy directives rather than market forces and/or economic interests alone best accommodates these requirements (see discussion on PLMCA immediately below). Accompanied by stable institutional, policy and legislative environments, these ingredients are all seen to beneficial to the development of more robust appraisal exercises better able to respond and adapt to emerging threats (and opportunities) posed by external project influences as well as internal.

The premise that MCA offers a more holistic approach to mega infrastructure appraisal than CBA and its derivatives was reinforced by the findings of an investigation carried out by the OMEGA Centre on behalf of the UK Institution of Civil Engineers and Actuary Faculty see Dimitriou et al., 2010). This involved an international panel of some 60 infrastructure professionals who by a clear majority (81 per cent) concluded that economic concerns should no longer be seen as the principal focus of the appraisal of mega infrastructure projects (see following paper). The experts interviewed disagreed with CBA's implicit premise that economic growth related concerns should be seen as the most important appraisal criteria and agreed with the proposition that a number of other performance criteria (beyond monetisation) should be considered in parallel with those focusing on economic and financial aspects. The survey findings also highlighted the wide support for the adoption of some kind of MCA approach to the assessment of mega infrastructure projects, especially MTPs. 55 percent of these same respondents deemed MCA to be particularly relevant to the appraisal of large-scale infrastructure projects, especially where it requires a perspective of how well a project performs in terms of addressing the multiple dimensions of sustainable development; economic, social, institutional and environmental. 


\subsection{The case for and background to Multi Criteria Analysis (MCA)}

\subsubsection{CBA, its derivatives and the origins of PLMCA}

Both the Editorial to this monograph and the preceding text of this paper make numerous reference to policy-led MCA (PLMCA), alluding briefly to its purported advantages over other MCA methods that do not explicitly emphasise the role of policy leadership and political interventions in appraisal nor to its potential to also act as risk/opportunity register for project investments. With the limitations to CBA cited above in mind, the ensuing discussion (supported by the papers which follow) make the case for the application of PLMCA as an enhanced platform for mega infrastructure appraisal.

The background and theory of MCA and its development to PLMCA are elaborated on in Paper 2 of this monograph and its operaltionalisation in Paper 3. The development of PLMCA, as earlier indicated, essentially has its roots jointly in the conclusions of the OMEGA Centre's international five year research programme in decision-making for MTPs (the OMEGA 2 Project) (see OMEGA Centre, 2012) and the work undertaken by the Centre for the UK Institution of Civil Engineers and Actuary Profession which investigated how the appraisal of major infrastructure projects can better incorporate social and environmental criteria of sustainable development (the OMEGA 3 Project) (see Dimitriou et al., 2010). Both sets of research, among other things, concluded that current conventional wisdom MTP project appraisal methods are not only too narrow in scope but inadequate in their treatment of risks, uncertainties and complexities to suitably inform key project stakeholders what constitutes a 'successful' project in more holistic terms beyond the metrics offered by the iron triangle perspective. These conclusions (lessons) especially point to CBA and its derivatives being incapable of responding robustly to unexpected events and sudden policy changes, external to project management decision-making. These were aspects highlighted in earlier research conducted by the OMEGA Centre in the OMEGA 1 Project which examined the treatment of risk, uncertainty and complexity in decision-making for megaprojects in a variety of disciplines and professions outside the infrastructure field where these characteristics have long time been seen as pivotal to their appraisal exercises (see Dimitriou et al., 2008).

The development of PLMCA was further inspired by the application of 'multi-criteria mapping' (MCM) to stakeholder decision-making for the agricultural sector which signalled a deviation from traditional MCA applications by use of a much simpler and more stripped down approach (see Sterling and Mayer, 1999The operationalization of PLMCA was subsequently advanced by the OMEGA Centre as a result of work commissioned by the European Investment Bank (EIB) (the OMEGA 12 Project) undertaken with a view to advising its Urban and Regional Development division (REGU) in the Bank's Project Directorate of how to apply PLMCA to the appraisal of major urban

Special 2016 Edition of The Journal of Research in Transportation Economics

'The Application of Policy-led Multi-Criteria Analysis to Megaproject Transport Infrastructure Appraisal' 
Paper 1: Presenting the Case for the Application of Multi-Criteria Analysis to Megaproject Infrastructure Appraisal Harry T. Dimitriou, E.John Ward and Marco Dean

investment projects (see Dimitriou et al., 2014). This study was informed by earlier efforts of the OMEGA Centre to operationalize the approach by means of role-playing multiple stakeholder decision-making applied to the Northern Line Extension (NLE) of London's underground (Dimitriou et al., 2013).

The findings of all these cited OMEGA Centre studies reinforce the contention presented by Rothengatter, (2008) and Vickerman (2008), among others that as important as traditional methods of economic appraisal are for particular project investors (especially project investors), there is a fast growing understanding among many international experts and stakeholders involved in the planning and appraisal of large-scale infrastructure projects that the use of appraisal methods that rely on outcomes and impacts expressed principally in monetary terms prevent decision makers from properly understanding the nature and balance of all the project appraisal factors involved. As earlier indicated, these reservations have not, however, prevented CBA and other related traditional monetised appraisal methodologies remaining the dominant approach used by bankers and investors in the appraisal of major infrastructure projects, particularly of MTPs. This is despite the fact that additional concerns have been expressed about the consequences of CBA exercises exhibiting a strong tendency to choose a single scenario rather than testing the robustness of a project under different plausible futures. This leads to downside scenarios of project outcomes frequently being inadequately addressed. The net result, it is contended, is that project 'outcomes' are expected to be more controllable and more in accordance with pre-determined plans, schedules and programmes than possible in reality (Dimitriou, 2009) or put another way, exhibit characteristics of optimism bias (Flyvbjerg et al., 2003).

\subsubsection{Need for more informed, transparent and holistic decision-making}

The above realities reinforce the view that mega infrastructure projects (including MTPs) require much broader and more dynamic framing than current planning and appraisal procedures permit (an argument further expanded elsewhere in this publication). They also highlight the importance of differentiating among the major risks (and opportunities) encountered in decision-making. Such differentiation needs to be made between those risks, uncertainties and opportunities derived from within the complexities of the project (see Chapman and Ward, 2011) and those arising externally from their changing context(s), including changes to the policy contexts surrounding project decision-making. Once again, these issues and how they are addressed in PLMCA is further elaborated on in the following papers.

Contending that the project lifecycle of mega infrastructure projects all too often appear to be fragmented and therefore fail to adequately take into account the influence of the dynamic environment(s) in which a project is planned, appraised and delivered, Allport (2011) reinforces the call for more holistic and context-sensitive planning and appraisal methodologies, supported by

Special 2016 Edition of The Journal of Research in Transportation Economics

'The Application of Policy-led Multi-Criteria Analysis to Megaproject Transport Infrastructure Appraisal' 
more effective and early engagement with stakeholders. This call also makes clear that future megaprojects, particularly MTPs, would benefit greatly from systematic lesson-learning and lessonsharing of past 'good practices' of the kind presented by the OMEGA Centre derived from its critical review of 30 MTP case studies in 10 countries in the developed world (OMEGA Centre, 2012). Such lessons need to focus on both qualitative and quantitative dimensions (monetised or otherwise) and seek to strike a balance between different interests, as well as long and short term priorities including the risks and uncertainties involved. These are lessons that have been identified elsewhere, as in the case of science and technology literature (Collingride, 1980; Renn, 1988) plus other sectors/disciplines (see Dimitriou et al., 2008).

In the belief that much more can (and should) be done to understand the risks, uncertainties and complexities in decision-making for large-scale infrastructure projects, particularly MTPs, the contributors to this monograph believe more energy needs to be invested into exploring, designing and providing more intelligent and transparent MCA frameworks together with their attendant processes (such as PLMCA) to facilitate better communications among key stakeholders. This is advocated on the grounds that this will enable participating stakeholders to better understand each other's positions, interests, problems and agendas concerning prospective developments when negotiation are underway. Helping parties understand as early as possible in the project lifecycle that sometimes one stakeholder's 'solution' is another's 'problem' or more significantly perhaps, one stakeholder's problem (or solution) is shared by others - can greatly facilitate stakeholders achieving consensus on critical issues as they arise (see Heydenreich, 2008). PLMCA greatly facilitates this sharing and exchange of perspectives under the guidance of a hierarchy of a given set of approved policies across different sectors and interests.

\section{References}

Adams, J., (1995) Risk, UCL Press, London

Alexander, E.R., (2006a) 'Evolution and Status: Where is Planning Evaluation Today and How did It get Here?' in Evaluation in Planning edited by E.R. Alexander, Ashgate, Aldershot

Alexander, E.R., (2006b) 'Problems and Prospects: Dilemmas in Evaluation and Directions for the Future' in Evaluation in Planning edited by E.R. Alexander, Ashgate, Aldershot

Allport, R.J. (2011) Planning Major Projects, Thomas Telford, London

Banister, D. and J. Berechman (2000) Transport Investment and Economic Development UCL Press, London

Baumol, W., (1968) 'On the Social Rate of Discount', American Economics Review, Vol.58, N. 4, pp. 788-802

Beesley, M.E., (1962) 'Some Aspects of the Economics of the M1', Journal of Industrial Economics, 0(3): pp. 204-208

Special 2016 Edition of The Journal of Research in Transportation Economics

'The Application of Policy-led Multi-Criteria Analysis to Megaproject Transport Infrastructure Appraisal' 
Paper 1: Presenting the Case for the Application of Multi-Criteria Analysis to Megaproject Infrastructure Appraisal Harry T. Dimitriou, E.John Ward and Marco Dean

Brent, R.S., (2006) Applied Cost-Benefit, Edward Elgar, Cheltenham.

Bristow, A. and J. Nellthorp, (2000), 'Transport project appraisal in the European Union', Transport Policy Journal, Vol. 7 (1): pp. 51-60

Brundtland G et al. (1987) Our Common Future: Report of the 1987 World Commission on Environment and Development, Oxford, Oxford University Press, Oxford

Cameron, J., (2011) 'Social Cost-Benefit Analysis - Principles' in Valuing Water, Valuing Livelihoods

- Guidance on Social Cost-benefit Analysis of Drinking-Water Interventions, with Special Reference to Small Community Water Supplies edited by Cameron, J., Hunter, P., Jagals, P., Pond, K., World Health Organization, IWA Publishing, London

Chapman, C. and S. Ward, (2011) How to Manage Project Opportunity and Risk, John Wiley, Chichester

Collingridge, D. (1980) The Social Control of Technology, Open University Press, Milton Keynes Dimitriou, H.T. (2009) 'Globalisation, Mega Transport Projects and Private Finance: Emerging challenges for 21st century', Proceedings, VREF 4th International Conference on Future Urban Transport, Gothenburg, April

Dimitriou, H.T., R.S. Oades and E.J. Ward (2008) 'Generic Lessons for Improving the Treatment of Risk, Uncertainty and Complexity of Mega Transport Projects', Working Paper \#4, OMEGA 1 Project,, OMEGA Centre, Bartlett School of Planning, University College, London, June

Dimitriou, H.T., R. Harman and E.J. Ward (2010) 'Incorporating Principles of Sustainable Development within the Design and Delivery of Major Projects: An International study with particular reference to major infrastructure projects', Report prepared for the Institution of Civil Engineering and Actuarial Profession as part of the OMEGA-RAMP Study, OMEGA 3 Project, OMEGA Centre, University College London, London

Dimitriou, H.T. and P.G. Wright (2013) Scoping Study on Applicability of Multi-criteria Analysis in Appraisal of Urban Projects, Report to REGU Division of Projects Directorate, European Investment Bank, OMEGA 8 Project, OMEGA Centre, Bartlett School of Planning, University College London, London, March

Dimitriou, H.T., P.G. Wright, E.J Ward, and M. Dean (2013) 'Policy Led Multi-Criteria Analysis (PLMCA) in the Planning, Appraisal and Delivery of Mega Infrastructure Projects: Dissemination to key stakeholders', NLE OMEGA Workshop, OMEGA 9 Project, Bartlett School of Planning, University College London, December

Dimitriou, H.T., P.G. Wright, E.J Ward, (2014) 'Multi Criteria Analysis Methodology for Project Appraisal in the Regional \& Urban Development Division', Report to REGU Division of Projects Directorate, European Investment Bank, OMEGA Project 12, OMEGA Centre, Bartlett School of Planning, University College London

De Brucker, K., Verbeke, A., Winkelmans, W. (1998) Sociaal-economische evaluatie van overheids investeringen in transportinfrastructuur, Garant, Leuven

Dobb, M. (1970) Welfare Economics and the Economics of Socialism, Cambridge University Press, Cambridge

Special 2016 Edition of The Journal of Research in Transportation Economics

'The Application of Policy-led Multi-Criteria Analysis to Megaproject Transport Infrastructure Appraisal' 
Paper 1: Presenting the Case for the Application of Multi-Criteria Analysis to Megaproject Infrastructure Appraisal Harry T. Dimitriou, E.John Ward and Marco Dean

DOT (2010) Guidelines for Cost Benefit Analysis, Department for Transport, HMSO, London

Eckstein, O. (1958) Water Resource Development: The Economics of Project Evaluation, Harvard University Press, Cambridge, Massachusetts

EC (2014) Guide to Cost Benefit Analysis of Investment Projects, European Commission, Brussels, December

Flyvbjerg B., N. Bruzelius and W. Rothengatter (2003) Megaprojects and Risk - An Anatomy of Ambition, Cambridge University Press, Cambridge

Foster, C. D., M.E. Beesley (1963) 'Estimating the Social Benefit of Constructing an Underground Railway in London, Journal of the Royal Statistical Society, Series A, Vol. 126, Part I

Funtowicz, S., J. Martinez-Alier., G. Mundaand J. Ravetz, (1999) 'Information Tools for Environmental Policy under Conditions of Complexity', European Environmental Agency, Experts' Corner, Environmental Issues Series, no 9

Gowdy, J.M. (2004) 'The Revolution in Welfare Economics and Its Implications for Environmental

Valuation and Policy', Land Economy, Vol. 80, n. 2, pp. 239-257

Grant-Muller, S.M., P. MacKie, J. Nellthorp and A. Pearman (2001), 'Economic Appraisal of European Transport Projects: The state-of-the-art revisited, Transport Reviews, Vol. 21 (2): pp 237261

Guba, E.G. and Y.S. Lincoln (1989) Fourth Generation Evaluation, Sage, London

Hammond, R.J., (1966) 'Convention and Limitation in Benefit-Cost Analysis', National Resources Journal, Vol. 6, n. 2, pp. 195-222

Hansson, S.O. (2007) 'Philosophical Problems in Cost-Benefit Analysis', Economics and Philosophy, Vol. 23, n. 2, pp. 163-183

Hausman, D.M. and M.S. McPherson (2006) Economic Analysis, Moral Philosophy, and Public Policy , Cambridge University Press, Cambridge

Hayashi, Y. and H. Morisugi (2000) 'International Comparison of Background Concept and Methodology of Transportation Project Appraisal', Transport Policy, Vol. 7: pp 73-88

Heydenreich, A-K., (2008) Organising a Multi-Stakeholder Process: Creating a paradoxical collaborative identity, PhD dissertation, Graduate School of Business Administration, Economics, Law and Social Sciences, University of St. Gallen, St. Gallen

Heinzerling, L., Ackerman, F. (2002) Cost-Benefit Analysis of Environmental Protection, Georgetown University, Washington D.C.

Hicks, J. (1939) The Foundations of Welfare Economics, The Economic Journal, Vol. 49, No. 1, pp.696-712

Hill, M. (1966) 'A Method for Evaluating Alternative Plans: The Goals-Achievement Matrix Applied to Transportation Plans, University of Pennsylvania, Philadelphia

Hill, M. (1968) 'A Goals-Achievement Matrix for Evaluating Alternative Plans', Journal of the American Institute of Planners, Vol. 34, n.1, pp. 19-29.

Hill, M., and M. Schechter(1971) 'Optimal Goal Achievement in the Development of Outdoor Recreational Facilities' in Urban and Regional Planning edited by A.G. Wilson, Pion, London 
Paper 1: Presenting the Case for the Application of Multi-Criteria Analysis to Megaproject Infrastructure Appraisal Harry T. Dimitriou, E.John Ward and Marco Dean

Hitch, C.J. and R.N. McKean, R.N. (1960) The Economics of Defence in the Nuclear Age, Harvard University Press, Cambridge, Massachusetts

HM Treasury (2003) The Green Book: Appraisal and Evaluation in Central Government, Treasury Guidance, HMSO, London

Hook, W. (2011) 'Use and Abuse of Economic Appraisal in Urban Transport Projects' in Urban Transport in the Developing World: A handbook of policy and practice edited by H.T. Dimitriou and R. Gakenheimer, Edward Elgar, Cheltenham

Irvin, G. (1978) Modern Cost-Benefit Methods:An Introduction to Financial, Economics and Social Appraisal of Development Projects., Macmillan Press Ltd., London

Jacobs., M. (1991) The Green Economy, London, Pluto Press, London

Kay, J. (2003) The Truth About Markets: Their Genius, Their Limits, Their Politics, Allen Lane, London Kaldor, N. (1939) Welfare Propositions in Economics and Interpersonal Comparisons of Utility, The Economic Journal, Vol. 49, No. 195) 49 (195): 549-552

Koopmans, C. and Rietveld, P., (2013) 'Long Term Impacts of Mega-Projects: The Discount Rate' in International Handbook on Mega-Projects edited by Priemus, H. and van Wee B., Edward Elgar, Cheltenham

Layard, R. (1972) Cost-Benefit Analysis, Penguin Education, Penguin Books, Harmondsworth

Leonard, H.B., and J.R. Zeckhauser (1983) Cost-Benefit Analysis Defended, Institute for Philosophy and Public Policy, Vol. 3, No.3

Levin, H.M. (1995) 'Cost-effectiveness Analysis in International Encyclopaedia of Economics of Education edited by M. Carnoy, Pergamon Press, Oxford

Lichfield, N. (1956) 'Economics of Planned Development' The Estates Gazette Ltd., London

Lichfield, N. (1960) 'Cost Benefit Analysis in City Planning', Journal of the American Institute of Planners, Vol. 26, No. 4, pp. 89-91

Lichfield, N. (1966) 'Cost Benefit Analysis in Town Planning: A Case Study: Swanley', Urban Studies, Vol. 3, pp. 215-249

Lichfield, N. 1970. Evaluation Methodology of Urban and Regional Plans: A Review, Regional Studies, vol. 4, No. 2, pp. 151-165

Lichfield, N., (1985) 'From Impact Assessment to Impact Evaluation' in Evaluation of Complex Policy Problems edited by A. Faludi, and H. Voogd, Delftsche Uitgewersmaatschappij, Delft

Lichfield, N. (1994) 'Community impact evaluation', Planning Theory, Vol. 12, pp. 55-79

Lichfield, N. (1996) Community Impact Evaluation, UCL Press, London

Litmam, T. (2008) 'A Good Example of Bad Transportation Performance Evaluation', Victoria Transport Policy Institute, Victoria, British Columbia

Litman, T. (2013) 'Critical Analysis of Conventional Transport Economic Evaluation,' Victoria Transport Policy Institute, Victoria, British Columbia

Litte, I.M.D. (1950) A Critique of welfare Economics, Clarendon Press, Oxford

Special 2016 Edition of The Journal of Research in Transportation Economics 
Paper 1: Presenting the Case for the Application of Multi-Criteria Analysis to Megaproject Infrastructure Appraisal Harry T. Dimitriou, E.John Ward and Marco Dean

Macharis, C. and J. Ampe (2007) 'The Use of Multi-Criteria Decision Analysis (MCDA) for the Evaluation of Transport Project: A review', Paper prepared for EURO XXII Conference, University of Economics, Prague

Makie, P. and J. Preston (1998) 'Twenty-One Sources of Error and Bias in Transport Project Appraisal', Transport Policy, Vol. 5, pp. 1-7

Massam, B. (1980) Spatial Search, Pergamon Press, Oxford

McAllister, D.M. (1982) Evaluation in Environmental Planning: Assessing Environmental, Social, Economic and Political Trade-Offs, MIT Press, Cambridge, Massachusetts

Meadows, D.H., D.L. Meadows, J. Randers, and W.W. Behrens III(1972) The Limits to Growth: A Report for the Club of Rome's Project on the Predicament of Mankind. Universe Books, New York

Mishan, E.J. (1967) The Costs of Economic Growth, Pelican Books, Harmondsworth, London

Mishan, E.J. (1988) Cost-Benefit Analysis, Allen and Unwin, London

Mitric, S. (2013) 'Two Strands in the Evaluation of Urban Transport Projects: Towards a Humane City', Novi Sad, 24th and 25th October

Munda, G. (1996) 'Cost-Benefit Analysis in Integrated Environmental Assessment: Some Methodological Issues', Ecological Economics, Vol. 19, n. 2, pp. 157-168

Munda, G. (2004) 'Social Multi-Criteria Evaluation (SMCE): Methodological Foundations and Operational Consequences', European Journal of Operational Research, Vol. 158, n. 3, pp. 662-677

Munda, G., P. Nijkamp and P. Rietveld (1994) 'Qualitative multi-criteria evaluation for environmental management', Ecological Economics, Vol. 10, No.2, pp. 97-112

Musgrove, R.A. (1969) 'Cost Benefit Analysis and the Theory of Public Finance' in Cost-Benefit Analysis edited by R. Layard, Penguin Books, Harmondsworth

Næss, P. (2006) 'Cost-Benefit Analyses of Transportation Investments: Neither Critical nor Realistic', Journal of Critical Realism, Vol. 5, No. 1, pp. 32-60

Nijkamp, P. and A. Van Delft (1977) Multi-criteria Analysis and Regional Decision-making, Studies in Applied Regional Science, Springer Press, Berlin

O'Connor M., S. Faucheux, G. Froger, S.O Funtowicz and G. Munda (1996) 'Emergent Complexity and Procedural Rationality: Post-Normal Science for Sustainability' in Getting down to Earth: Practical Applications of Ecological Economics edited by R. Costanza, O. Segura and J. Martinez-Alier, Island Press, Washington D.C.

OECD (2006) Cost-Benefit Analysis and the Environment: Recent Developments, Organisation for Economic Cooperation and Development, Paris

Oka, T. (2003) 'Effectiveness and Limitations of Cost-benefit Analysis in Policy Appraisal', Government Auditing Review, Vol. 10. pp. 71-83

Olivera, V., Pinho, P. (2010) Evaluation in Urban Planning: Advances and Prospects. Journal of Planning Literature, Vol. 20, n. 10, pp. 1-19

Special 2016 Edition of The Journal of Research in Transportation Economics

'The Application of Policy-led Multi-Criteria Analysis to Megaproject Transport Infrastructure Appraisal' 
Paper 1: Presenting the Case for the Application of Multi-Criteria Analysis to Megaproject Infrastructure Appraisal Harry T. Dimitriou, E.John Ward and Marco Dean

OMEGA Centre (2012) Mega Projects: Executive Summary - Lessons for Decision-makers: An Analysis of Selected International Large-Scale Transport Infrastructure Projects, Bartlett School of Planning, University College London, London

Page, M., J. Forester and P. Jones, P. (2007) Enhanced Appraisal Tools: Deliverable $G$ of the DISTILLATE (Design and Implementation Support Tools for Integrated Local Land use, Transport and the Environment) Research Programme. [online] Available: http://www.distillate.ac.uk [accessed 15th June 2013]

Patel, M.B. and P.G.W.Morris (1999) Guide to the Project Management Body of Knowledge, Centre for Research in the Management of Projects, University of Manchester, Manchester

Pearce, D. (1998) 'Cost-Benefit Analysis and Environmental Policy', Oxford Review of Economic Policy, Vol. 14, n. 4, pp. 84-100

Pearce, D., G. Atkinson and S. Mourato (2006) Cost-Benefit Analysis and the Environment, Organisation for Economic Co-operation and Development (OECD), Paris

Pearce, O. (2008) 'Holistic assessment of sustainability and its application at Halcrow,' The Journal of Corporate Citizenship, Issue 30, pp37-65

Peters, G.H., (1968) Cost-Benefit Analysis and Public Expenditure, Institute of Economic Affairs, London

Porter, T.M., (1995) Trust in Numbers: The Pursuit of Objetivity in Science and Public Life, Princeton University Press, New Jersey

Prest A.R. and R. Turvey (1965) 'The Main Questions' in Cost-Benefit Analysis edited by Layard, R. Penguin Education, Penguin Books, Harmondsworth

Priemus, H. (2008) 'How to Improve the Early Stage of Decision-Making on Mega-Projects' in Decision-Making on Mega-Projects: Cost-Benefit Analysis, Planning and Innovation edited by Priemus, H., Flyvbjerg, B. and van Wee, B., Edward Elgar, Cheltenham

Renn, O. (1998) 'Three decades of risk research: accomplishments and new challenges', Journal of Risk Research, 1, pp. 49-71.

Rietveld, P. (2013) 'Appraisal Methods for Transport Policy' in B. van Wee, B. Annema, J.A., and D. Banister (eds.) The Transport System and Transport Policy, An Introduction, Cheltenham, Rogers, M. and A. Duffy (2012) Engineering Project Appraisal, Blackwell Science, Oxford

Rosen, R. (1977) 'Complexity as a System Property', International Journal of General Systems, Vol. 4, No. 3, pp. 227-232

Rothengatter, W. (2008) 'Innovation in the Planning of Mega-Projects' in Decision-Making on Mega-

Projects: Cost Benefit Analysis edited by H. Priemus, B. Flyvbjerg and B. van Wee, Edward Elgar, Cheltenham

Sager, T. (2003) 'Rationality Types in Evaluation Techniques:The Planning Balance Sheet and the Goals Achievement Matrix, European Journal of Spatial Development, Vol. 2, pp.1-30

Sen, A.K. (1980) 'Personal Utilities and Public Judgments: Or What's Wrong with Welfare Economics', Economic Journal, Vol. 89, pp. 537-558

Simon, H.A. (1976) Administrative Behaviour, New York Free Press, New York

Special 2016 Edition of The Journal of Research in Transportation Economics

'The Application of Policy-led Multi-Criteria Analysis to Megaproject Transport Infrastructure Appraisal' 
Paper 1: Presenting the Case for the Application of Multi-Criteria Analysis to Megaproject Infrastructure Appraisal Harry T. Dimitriou, E.John Ward and Marco Dean

Snell M. (1997) Cost Benefit Analysis for Engineers and Planners, Thomas Telford Ltd., London Söderbaum, P. (1998) 'Economic and Sustainability: An Actor-Network to Evaluation' in Evaluation in Planning: Facing the Challenge of Complexity edited by N. Lichfield, A. Barbanente, AD. Borri, A. Khakee, and A. Prat, A., Kluwer Academic Publishers, Netherlands.

Sinnott-Armstrong, W. (2014) 'Consequentialism', The Stanford Encyclopedia of Philosophy, edited by Edward N. Zalta, http://plato.stanford.edu/archives/spr2014/entries/consequentialism/

Stirling, A. (1998) 'Risk at a turning point?', Journal of Risk Research, 1, 97-109.

Stirling, A., and Mayer, S. (1999) 'Rethinking Risk: A pilot multi-criteria mapping of a genetically modified crop in agricultural systems in the UK', Science Policy Research Unit Report No 21, University of Sussex, Brighton

Stirling, A. (2008a) 'Opening up or Closing down: Participation, pluralism and diversity in the social appraisal of technology', Journal of Science, Technology and Human Values, Vol. 33, pp.262294

Stirling, A., (2008b). 'Precaution, and the Politics of Technological Risk: Converging Implications in Evolutionary and Social Scientific Perspectives', Annals of the New York Academy of Science, Vol. 1128, pp. 95-110

Systems Centre and The Bartlett (2013) A Proposed Interdependency Planning and Management Framework: Development and Application for UK Infrastructure, Final Report to HM Treasury and Infrastructure UK, Systems Centre, University of Bristol and OMEGA Centre and School of Project and Construction Management, The Bartlett, University College London, University of Bristol, Bristol, September

Tisdell, C.A. (2005) The Economics of Environmental Conservation, Edward Elgar, Cheltenham UN Habitat (2013) Planning and Design for Sustainable Urban Mobility: Global Report on Human Settlements 2013, UN Habitat, Nairobi

US Congress (1969) 'The Planning-Programming-Budgeting System: Progress and Potentials' in Program Budgeting and Benefit-Cost Analysis: Cases, Texts and Readings The Planning edited by H.H. Hinrichs and G.M. Taylor, Goodyear Publishing Co., Pacific Palisades, California van Wee, B. (2011) How Suitable is CBA for Ex-Ante Evaluation of Transport Projects and Policies? A Discussion from the Perspective of Ethics, Transport Policy, Vol. 19, No. 1, pp. 1-7

van Wee, B. and P. Rietveld (2013) 'CBA: Ex-Ante Evaluation of Mega-Project' in International Handbook on Mega-Projects, Edward Elgar, Cheltenham

van Wee, B., and Tavasszy L.A. (2008) 'Ex-Ante Evaluatation of Mega-Project: Methodological Issues and Cost-Benefit Analysis' in Decision-Making on Mega-Projects: Cost-Benefit Analysis, Planning and Innovation edited by Priemus, H., B. Flyvbjergand B. van Wee, Edward Elgar, Cheltenham

Vasconcellos, E. (2003) 'Inclusion of Social Benefits in Road Transport Planning', unpublished paper sent by author to H.T. Dimitriou

Special 2016 Edition of The Journal of Research in Transportation Economics

'The Application of Policy-led Multi-Criteria Analysis to Megaproject Transport Infrastructure Appraisal' 
Paper 1: Presenting the Case for the Application of Multi-Criteria Analysis to Megaproject Infrastructure Appraisal Harry T. Dimitriou, E.John Ward and Marco Dean

Véron-Okamoto, A. and K. Sakamoto (2014) 'Toward a Sustainability Appraisal Framework for Transport', ADB Sustainable Development Working Paper Series, No. 31, Asian Development Bank, Manila, January

Vincke, P. (1992) Multicriteria Decision-Aid. John Wiley \& Sons, New York

Vining, A.R. and D.L. Weimer, D.L. (1992) 'Welfare Economics as the Foundation for Public Policy Analysis: Incomplete and Flawed but nevertheless Desirable', Journal of Socio-Economics, Vol. 21, No. 1, pp. 25-37

Vickerman, R. (2008) 'Cost-Benefit Analysis and the Wider Economic Benefits from Mega-Projects' in Decision-Making on Mega-Projects: Cost Benefit Analysis edited by H. Priemus, B. Flyvbjerg and B. van Wee, Edward Elgar, Cheltenham

Wideman, R.M., (2004) 'The Role of the Project Life Cycle (Life Span) in Project Management - A review of literature Over Three Decades' [online] Available: http://maxwideman.com/papers/ [accessed 5th July 2013]

Word Count: 14,165 